\title{
LABORATORY INVESTIGATIONS OF THE ASSESSMENT AND PRECONCENTRATION OF COASTAL SILLIMANITE
}

\section{R. BHIMA RAO}

Regional Research Laboratory, Council of Scientific \& Industrial Research, Bhubaneswar 751 013, India

(Received May 9, 1997, in final form July 24, 1997, accepted August 14, 1997)

\begin{abstract}
$\underline{\text { Abstract }}$
India has a high demand for refractory minerals. Sillimanite is one of the minerals having high refractory characteristics. In this paper, the availability of sillimanite along the coastal belt of Orissa coast and its laboratory beneficiation tests are discussed. The results indicate that +0.5 $\mathrm{mm}$ contain shell, $2.8 \mathrm{~s}$.g. floats contain quartz, magnetic heavies contain ilmenite and garnet and the non-magnetic heavies contain mainly sillimanite. The raw sand contains $4 \%$ sillimanite and the preconcentrated non-magnetic heavies contain 55 to $65 \%$ sillimanite. This product after flotation is suitable for industrial use.
\end{abstract}

\section{INTRODUCTION}

The placer and shore sands are preconcentrated heavy minerals which are well liberated from the country rock [1]. The geomorphic natural phenomenon for concentration of these minerals consists disintegration of parent rock by weathering process, comminution and transportation by rivers and concentration by heavies by thin-film concentration.

Sillimanite is one of the most potentially available minerals in these sands which has high demand from many refractory industries. This mineral also occurs in the metamorphosed gneiss and schistose rocks. However, comminution and processing 
are most expensive for liberating the desired sillimanite from these rocks. Department of Atomic Energy has done an extensive study on the coastal sands of Andhrapradesh [2]. National Institute of Oceanography, Goa and Regional Research Laboratory, Bhubaneswar have jointly studied the off-shore sands of the west coast of India [3]. Detailed studies with particular reference to assessment and beneficiation studies of sillimanite of the Orissa coast have not been, however, attempted.

In this paper, an attempt is being made to assess the distribution, association and quantity of sillimanite available along the Orissa coastal belt of Konark-Puri. Preconcentration techniques and beneficiation methods on this shore sand are also discussed.

\section{MATERIALS AND METHODS}

Shore sand samples were collected along the river mouths of 30 kilometer distance of Puri District, Orissa, India. For this purpose, systematic auger sampling was carried out in a grid pattern, down to ground water table from frontal and rear dunes of the shore. Initially, one composite sample was prepared and subjected to wet size classification at $0.5,0.4,0.3,0.2,0.1$ and $0.05 \mathrm{~mm}$ sieve openings.

The $+0.5 \mathrm{~mm}$ size contains mostly shell and -0.05 size contains mostly clay along with a few heavy minerals. The $-0.5 \mathrm{~mm}$ size fraction was subjected to heavy media separation at $2.8 \mathrm{sg}$ by using an organic liquid bromoform. In this case, about 500 grams of the sample were poured into five $250 \mathrm{ml}$ beakers and thoroughly stirred by a glass rod. The sample was allowed to settle till a clear separation of heavies and lights was observed. After separation of the lights from the heavies, bromoform was filtered and these products were thoroughly washed using acetone. The weights were recorded after drying in an oven. The lights, containing mainly quartz, were rejected.

Based on these observations, all the representative samples were classified at 0.5 $\mathrm{mm}$ and subjected to heavy media separation as earlier at $2.8 \mathrm{sg}$. The heavies were grouped into eight categories depending on the percentage of heavies present in 
each sample. These are: 1) raw sand, 2) $5 \%$ heavies, 3) $10 \%$ heavies, 4) $15 \%$ heavies, 5) $20 \%$ heavies, 6) $25 \%$ heavies (<30\%), 7) high clay and 8 ) high shell content. Size analysis of all eight samples was carried out using standard sieves. Each close size fraction was subjected to magnetic separation using permanent roll magnetic separator supplied by Ore Sorters (Australia) Pty. Ltd. The non-magnetic heavies were sillimanite, zircon and monazite. Distribution of each mineral in each size fraction was counted by microscope.

\section{RESULTS AND DISCUSSION}

The raw sand contains quartz as the major gangue mineral, followed by shell. The other minerals are ilmenite, garnet, rutile, sillimanite, kyanite, zircon and monazite. The microscopic studies confirm these findings and the mineralogical composition of raw sand is shown in Figure 1. It can be seen that the sand contains $76 \%$ quartz, $8 \%$ ilmenite, $3 \%$ garnet, $4 \%$ sillimanite and $8 \%$ of clay, shell and heavy minerals.

Fig. 1. Mineralogical model analysis of shore sand

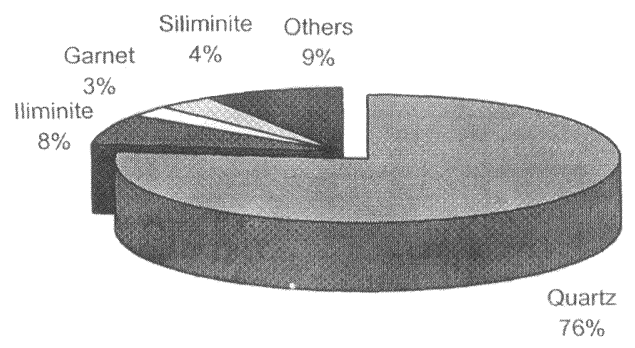

Figure 2 represents the distribution of the heavies in the raw sand. This Figure indicates that the maximum amount of heavies is present at $2 \mathrm{~mm}$ size fraction. The percentage of heavy minerals, namely ilmenite, garnet, sillimanite and others in five categories of samples $(5 \%, 10 \%, 15 \%, 20 \%, 25 \%$ heavies) is shown in Figure 
3. It can be seen that the percentage of ilmenite and sillimanite is almost equal in quantity at $10 \%$ heavy mineral sample. The sillimanite trend is decreasing with increasing content of ilmenite in other heavy mineral samples.

Fig. 2. Distribution of heavies in raw sand (Size, below $0.5 \mathrm{~mm}$ )

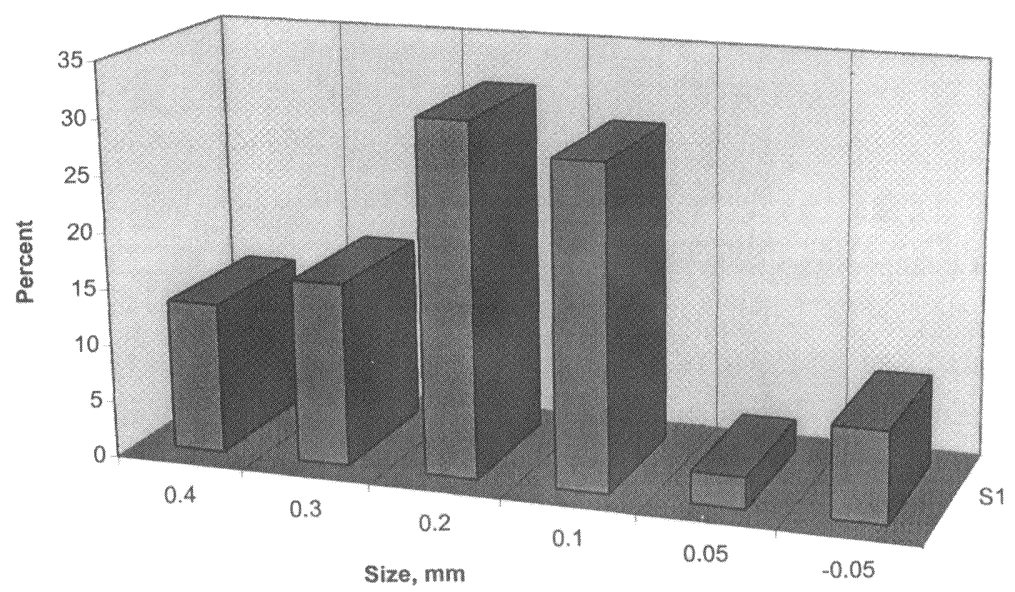

Fig. 3. Heavy mineral distribution at different grade samples

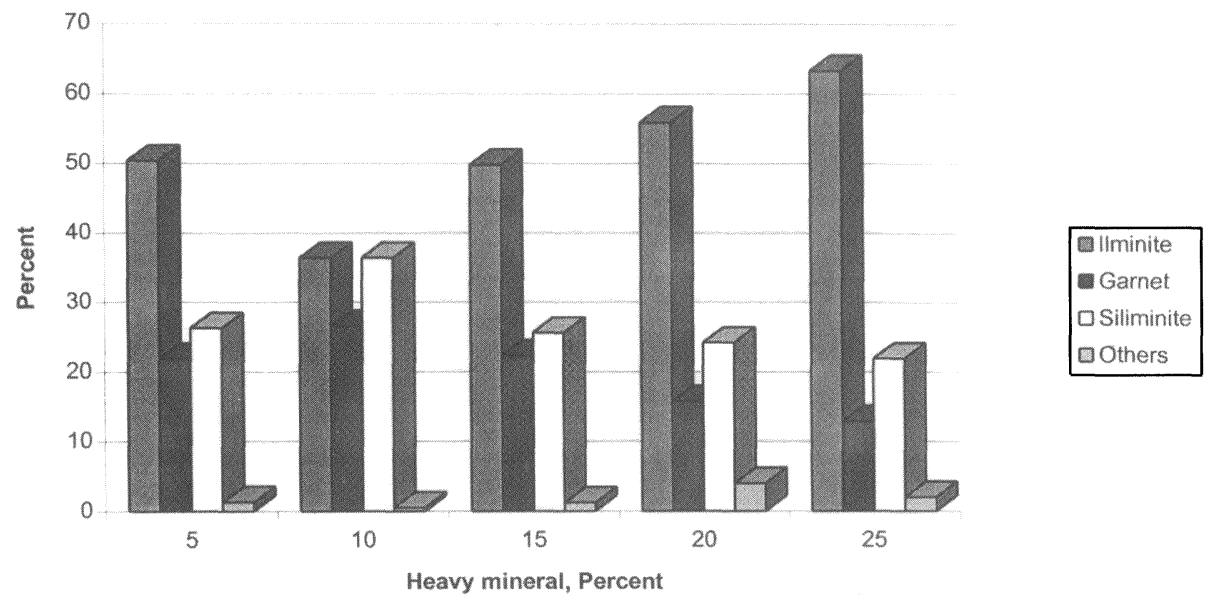

Figures 4 to 7 indicate size distributions of total non-magnetic heavies and sillimanite in samples 2) to 8 ). It can be clearly seen that the non-magnetic 
Fig.4. Siliminite distribution in non magnetic hevies (Sample 5\% heavies)

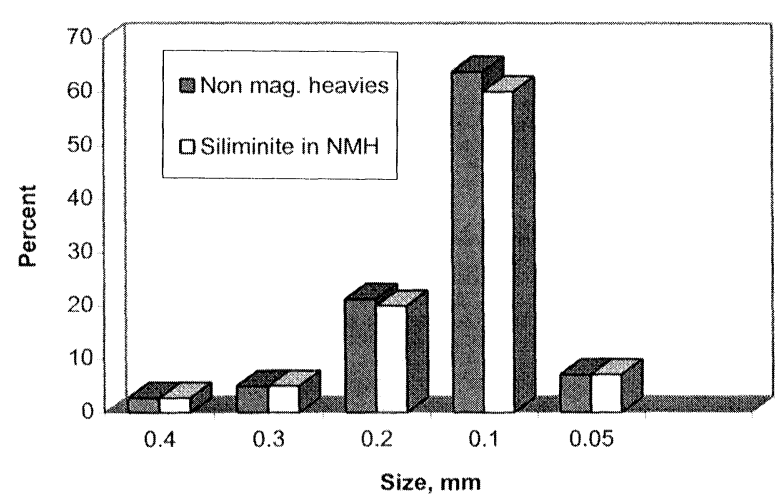

Fig. 5. Siliminite distribution in non magnetic heavies (Sample 25\% heavies)

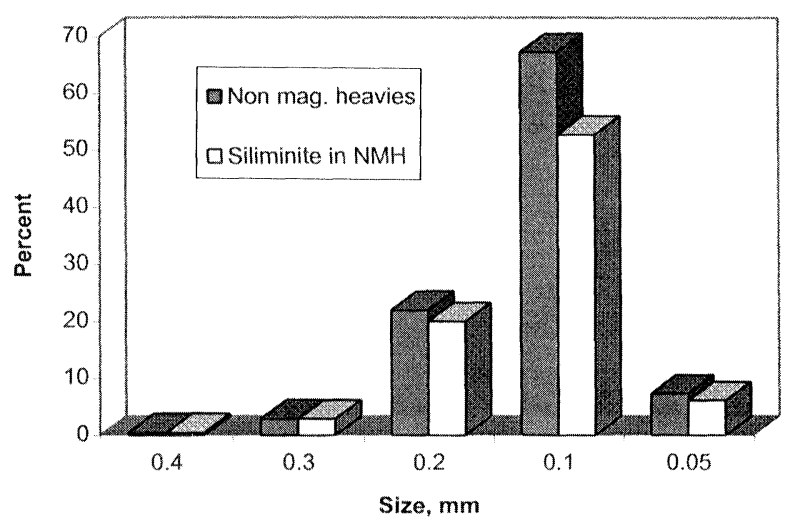

heavies contain mostly sillimanite except at $0.2 \mathrm{~mm}$ and $0.1 \mathrm{~mm}$ size fractions. Interestingly, it can also be seen that the maximum amount of sillimanite is present at $1 \mathrm{~mm}$ size fraction. According to Gaudin, this type of sharp cuts represents liberation. However, the sillimanite distribution in the non-magnetic 
heavies is almost similar in samples of $5 \%$ to $25 \%$ heavies, the highest clay and shell content samples. On average, the non-magnetic heavies contain 55 to $65 \%$ sillimanite. Thus, based on the results, a flowsheet is suggested as shown in Figure 8.

Fig. 6. Siliminite distribution in non magnetic heavies (Sample High shell)

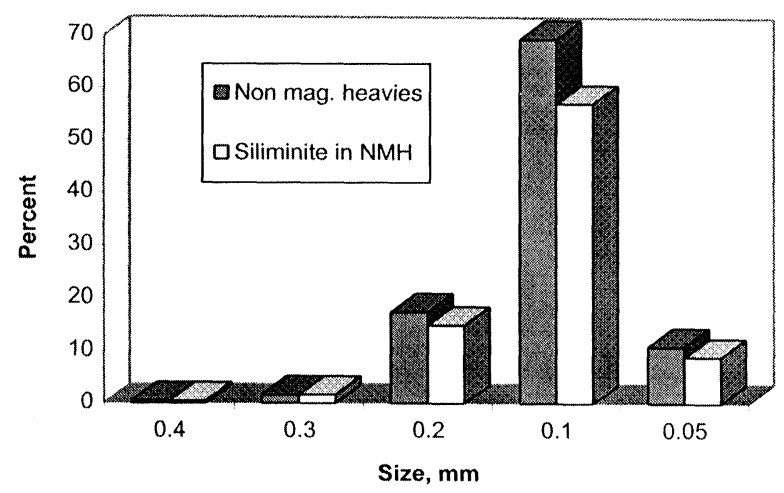

Fig. 7. Siliminite distribution in non magnetic heavies (Sample high clay)

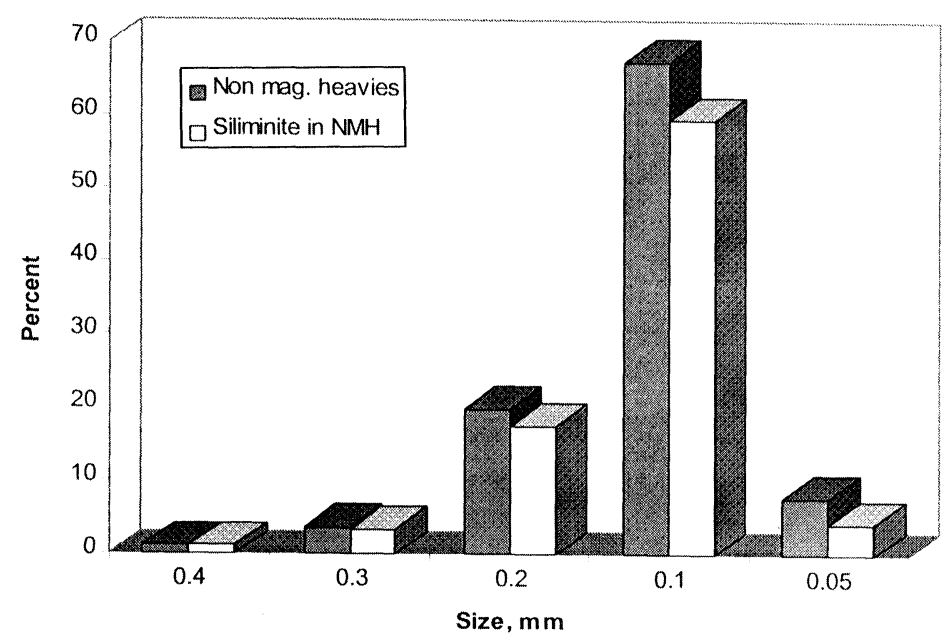




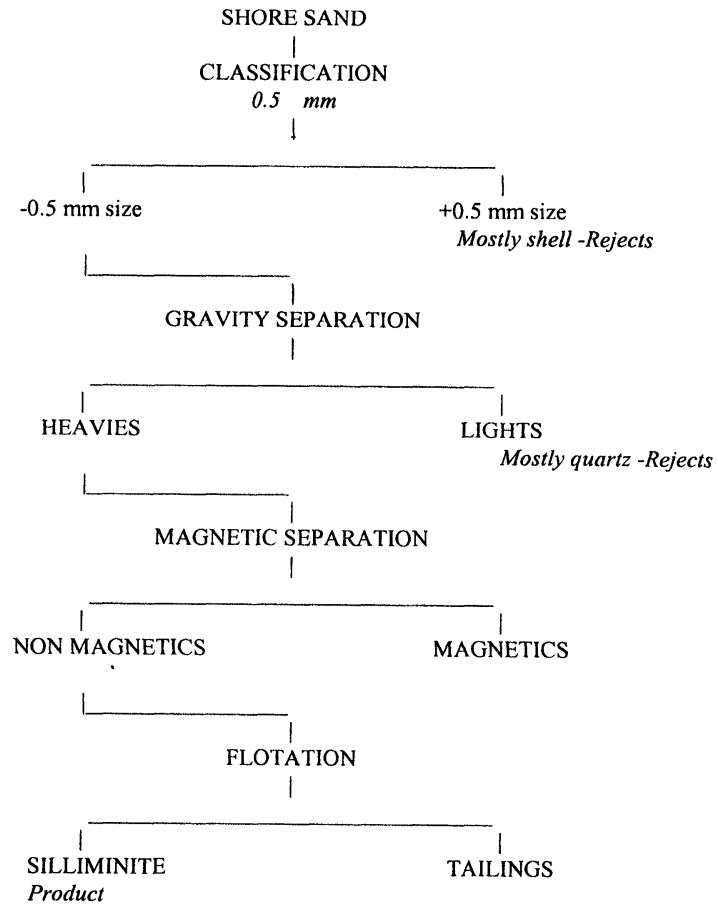

Fig. 8 The conceptual flowsheet for the recovery of shore sillimanite

\section{CONCLUSIONS}

The results of these investigations indicate that most of the shells could be rejected at $0.5 \mathrm{~mm}$ size. The sink-float separation of $-0.5 \mathrm{~mm}$ composite raw sand represents $23 \%$ heavies which contain $4 \%$ sillimanite. Typical sample, $10 \%$ heavies, contains equal amount of ilmenite and sillimanite. The non-magnetic heavies in the $5 \%$ heavies category sample contain 55 to 655 sillimanite. The trend is similar at $10 \%, 25 \%$, high shell and clay content samples. Thus, pre-concentration by cyclones followed by tabling, magnetic separation of the heavies and flotation of the non-magnetic heavies is the best approach for the recovery of sillimanite. 


\section{ACKNOWLEDGMENT}

The author wishes to thank the Director for his permission to publish the paper.

\section{REFERENCES}

[1] Borreswara Rao C., Current Sciences 26 (1957), 27

[2] Gajapathi Rao, Ravi G.S., Ali M.A., Naveentham K.V. and Kaul R: Gravity Concentration, RRL, IIM, Bhubaneswar 1972, p. 272

[3] Sahoo R.K.,Acharya B.C. Misra S.K., Das S.K., Bhima Rao R. and Sastri S.R.S.: Development of Marine and Forest Resources, RRL Bhubaneswar 1985 , p. 18

R. Bhima Rao: for biography see Magn. Electr. Sep. 8 (1997), 115

Keywords: Sillimanite, shore sand, heavy media separation, magnetic separation, flotation 